

\section{Páramo de oro: \\ neoextractivismo y movilización social ambientalista en Santurbán}

Por Álvaro Acevedo Tarazona* y Andrés David Correa Lugos**

Resumen: el objetivo de este artículo es analizar la problemática presentada en el Páramo de Santurbán con la propuesta de megaminería a cielo abierto de la trasnacional Greystar en el año 2011. Esta situación llevó a un clima de movilizaciones ambientalistas en el centro urbano más próximo a Santurbán, Bucaramanga, y a una tensión política entre dirigentes que se mantiene hasta hoy. Esta investigación recurre al contraste de la fuente primaria (periódicos) con el fin de construir un discurso que sobrepase el carácter noticioso y elabore una aproximación comprensiva histórica de coyunturas actuales con problemáticas de mediana duración y repercusiones en la cotidianidad local.

Palabras clave: globalización, glocalidad, movilización, neoextractivismo

\section{Páramo de oro: neo-extractivism and environmental social mobilization in Santurbán}

Abstract: The objective of this article is to analyze the problematic presented in the Paramo of Santurbán with the proposal of open Mega Mining of the transnational Greystar in 2011. This situation leads to a climate of environ-

* PhD. en Ciencias de la Educación de la Universidad Pedagógica y Tecnológica de Colombia. Doctor en Historia de la Universidad de Huelva (España). Profesor titular de la Universidad Industrial de Santander, Colombia. Correo electrónico: tarazona20@gmail.com

** Historiador y archivista de la Universidad Industrial de Santander. Miembro activo del grupo de investigación Políticas, Sociabilidades y Representaciones HistóricoEducativas. Correo electrónico: andrescorrealugos@outlook.com 
mental mobilizations in the urban center closest to Santurbán, Bucaramanga and a political tension between leaders that remains today. This research uses the contrast of the primary source (newspapers) in order to construct a discourse that surpasses the news character and elaborates a comprehensive historical approximation of current conjunctures with problems of medium duration and repercussions in the local quotidian.

Keywords: globalization, glocality, mobilization, neoextractivism

Cómo citar este artículo: Acevedo Tarazona, Álvaro y Correa Lugos, Andrés. (2017). Páramo de oro: neoextractivismo y movilización social ambientalista en Santurbán. Revista Controversia, 208, 195-220.

Fecha de recepción: 20 de enero del 2017

Fecha de aprobación: 10 de abril del 2017

\section{Introducción}

71 propósito de este artículo es establecer una línea argumental 4 que analice los movimientos sociales ambientalistas a partir de los acontecimientos ocurridos en el año 2011 en la zona geológica y ambiental conocida como Páramo de Santurbán y el área metropolitana de Bucaramanga. Estas movilizaciones son consecuencia del proyecto de megaminería a cielo abierto liderado por la multinacional Greystar. La importancia de esta investigación radica en que la zona es un referente en las luchas ambientales, además ha logrado movilizar a miles de personas en torno al ideal de proteger las fuentes hídricas y también trajo al debate la delimitación de páramos en la Corte Suprema de Justicia.

En la disputa por la explotación del páramo sobresalen dos posturas: la primera, encabezada en su mayoría por los ciudadanos del área metropolitana de Bucaramanga, desaprueba cualquier explotación minera en la zona; la segunda, perteneciente a los pobladores de la provincia 
de Soto Norte, en especial a los de los municipios de Vetas y California, reconoce una tradición minera histórica y rechaza la presencia de multinacionales. Así la dinámica social se complejiza si a todo esto se suma el abandono estatal, la violencia y la desigualdad social, factores que aprovecha muy bien la multinacional Greystar para ganar la aprobación de algunos de los pobladores de la zona.

Este artículo ubica la expansión neoextractivista en el país con la apertura económica ejecutada por el presidente César Gaviria Trujillo en la década de 1990, para ello, se hace referencia al proyecto transminero mejor conocido como Proyecto Angostura. Dicho proyecto se encuentra vigente desde el año de 1994, pero solo hasta el año 2011 se tuvo conocimiento por parte de las personas que habitan en el área metropolitana de Bucaramanga sobre sus consecuencias. A partir de este momento, empezó la tensión entre los habitantes de Vetas y California, que son los principales municipios cercanos al Páramo de Santurbán, y los habitantes del centro urbano de Bucaramanga. Esta tensión se acentuó gracias al manejo que los medios de comunicación le dieron a esta problemática y se agudizó por las concesiones mineras que comprometen no solo la calidad del agua y el paisaje del entorno, sino también la economía y la subsistencia de pobladores que dependen del oficio de la extracción aurífera artesanal.

En este caso, la defensa del agua como bien común entra en disputa con el derecho al trabajo. En medio de esta fricción entre lo común y lo necesario, hacen su aparición los gremios y los partidos políticos a favor de cada uno de los enfrentados. La movilización ambiental es muy distinta porque no hay dos antagonistas. Son muchos los factores que influyen, y el desconocimiento de la situación del otro hace que los discursos se radicalicen. Más que una movilización antisistémica es una movilización antiglobalizada, las personas en Soto Norte tienen la añoranza por los tiempos pasados, cuando cada uno trabajaba con sus manos en una mina común y la vida era más sencilla. 
Este artículo es producto del proyecto de investigación El Páramo de Santurbán y los derechos de los pobladores en un contexto de conservación, financiado por la Universidad Industrial de Santander UIS. Su objetivo es analizar las acciones colectivas generadas a partir de la tensión existente entre los proyectos de megaminería y el rechazo por parte de pobladores tanto de los municipios de Vetas y California como del área metropolitana de Bucaramanga. La investigación parte de una metodología cualitativa con enfoque hermenéutico, que da prioridad al uso de fuentes primarias (periódicos) entre los años1994 y 2015. El plano temporal está marcado por tres acontecimientos: la implementación de una política extractivista en el país (1994-2010); las grandes movilizaciones en contra del proyecto de Greystar (2011-2014) y la delimitación de los páramos y el cambio de nombre de la compañía a Eco Oro (2015). También se hacen entrevistas semiestructuradas a líderes y personas involucradas en la problemática en Vetas, California y Bucaramanga. La información recolectada es triangulada y analizada con base en la teoría de movimientos sociales.

\section{Marco teórico: movimientos ambientalistas, neoextractivismo y páramo}

Las movilizaciones ambientalistas como tantas otras de la actualidad modifican de manera sustancial la forma en que los actores sociales se ven a sí mismos y la interrelación con otros actores sociales y con el medio ambiente. La reconfiguración de estas nuevas correspondencias, entre ellas las nuevas formas de protesta, es acelerada por el impulso de las lógicas neoliberales que conducen al ser humano a una individualización de sus pretensiones y la capitalización de formas antes inexploradas por el capitalismo (Han, 2013). Esta reconceptualización de la cotidianidad sumerge a los actores sociales en un estado de continuo suspenso y malestar; ambas pulsiones se manifiestan, entonces, en las protestas y las movilizaciones. La movilización es un imperativo y un común denominador en la historia del siglo xx y de la historia del tiempo presente, pues se convierte en uno de los pocos fenómenos co- 
lectivos en el que es posible evidenciar de manera directa el accionar colectivo y pone en tela de juicio los acercamientos teóricos que hablan del fin de las masas, la historia y, sobre todo, de la colectivización de necesidades y pretensiones con el fin de lograr un objetivo.

La aparición de los movimientos ambientalistas y ecológicos tiene dos causas: la primera se remonta a la década de 1960 y se explica desde la teoría social, cuando el movimiento social moderno por excelencia, es decir el obrero, ramificó sus intereses hacia distintas esferas de la sociedad como las culturales, cívicas, de género y ambientales; en ese momento, se inició todo un proceso de atomización de las molestias, de las pretensiones y, sobre todo, del pliego de peticiones. Esta tendencia va de la mano de la implementación de una lógica demócrata liberal: "la derivación del capitalismo industrial a una versión primigenia del capitalismo de consumo y la consolidación de un modelo globalizante con organizaciones transnacionales" (Castro-Gómez, 2015).

La aparición de estos nuevos movimientos sociales marcó un punto de inflexión o más bien una bifurcación ${ }^{1}$ del movimiento social que, hasta ese momento, se caracterizó por tener una filiación política e ideológica de izquierda o comunista y un modus operandi en el que la lucha antisistémica definió las formas de protesta y resistencia. La deriva del movimiento social hacia otras manifestaciones de fenómenos colectivos es un resultado histórico que se explica filosóficamente como la puesta en práctica de un modelo utópico que conllevó a la desilusión distópica, por ejemplo: la alegría creativa del futurismo ruso se puso al servicio del terror bolchevique, las revueltas igualitarias se transformaron en dictaduras de Estado como en China, y la Revolución cultural terminó suministrando la fuerza de trabajo al nuevo capitalismo (Berardi,

1 Término usado por el filósofo Franco Berardi para explicar el desencanto que produce la puesta en práctica de algunos ideales de los movimientos sociales. Estos ideales son, de alguna manera, aprovechados por el sistema para reproducir nuevas formas de dominación que dan libertades o derechos a algunas facciones, pero perjudican a otras como efecto colateral. 
2007). En Colombia, el movimiento social se produjó en su mayoría por la fuerza disgregativa de la violencia y el terror ejercido desde el Estado con iniciativas como el Estatuto de Seguridad (1978) que castigaba cualquier señal de participación popular masiva.

La segunda causa en el origen de este movimiento puede entenderse como un producto implícito de la anterior. Con el acelerado desarrollo industrial, científico y tecnológico, la humanidad se expone a una realidad incómoda: las fuerzas que está usando el hombre lo pueden conducir a la aniquilación de la especie y del planeta tierra. Esta conciencia tomó fuerza en las décadas de 1960 y 1970 con las pruebas nucleares y el extractivismo exacerbado por empresas transnacionales en países del Tercer Mundo (Carson, 2005). De igual manera, el consumo exagerado de combustibles fósiles y el uso indiscriminado de gases tóxicos como los clorofluorocarbonos (CFC) aceleran, según estudios científicos, el daño en la capa de ozono y el efecto invernadero. Los resultados de estos estudios se han convertido en un importante insumo para que grupos ambientalistas se movilicen y creen conciencia tanto de empresarios e industriales como de consumidores. Lógicamente, esta situación es evidente en los países del primer mundo, mientras que en las latitudes latinoamericanas las preocupaciones están concentradas en otro tipo de problemáticas como la violencia y la desigualdad social.

El teórico social Alberto Melucci profundiza en el estudio de los movimientos sociales ambientales al puntualizar que estos difieren de los otros por la atención despertada en los medios de comunicación y en la conciencia civil. Todo el mundo reconoce la importancia de la naturaleza sin interesar el espectro político e ideológico. Para Melucci la cuestión ecológica no aplica directamente a los problemas ambientales, más bien es un síntoma del cambio en la realidad social y cultural que concibe el ambiente (Melucci, 2010, p.148). ¿Por qué solo hasta el año 2011 los habitantes de Bucaramanga se preocuparon por la problemática de Santurbán? Según Melucci, porque esta es la manifestación del síntoma de una interdependencia cíclica de las realidades: los actores 
colectivos son conscientes de que la historia y la supervivencia de la humanidad no son lineales, se necesita de todos los sistemas y hábitats para desarrollarse y garantizar la supervivencia de la especie.

Se podría considerar que los movimientos ambientalistas van más allá de los medios-fines del sistema capitalista, pues se preguntan y movilizan por las finalidades. Una vez se resuelve un proyecto extractivista, ¿qué queda? Esa proyección del futuro es la que hace que lo ambiental centre su atención más allá de cuestiones políticas y económicas, es decir, en cuestiones casi biológicas como "el sustento básico para sobrevivir”. El planeta ya no es un espacio físico, es un espacio social unificado (Melucci, 2010, p.149). La globalización convierte al mundo en una aldea global a una velocidad expresa. El cambio es tan vertiginoso que muchas de estas realidades se desconocen. El conflicto aparece cuando trasnacionales, forjadas en plena globalización, irrumpen en sociedades con un desarrollo mediano - como el de Bucaramanga-, o donde hay "ausencia” de progreso — como en Vetas y California-; en ese orden de ideas, no hay una sincronía entre los ciudadanos de la aldea global, pues se presenta una realidad compartida entre sociedades globalizadas, mientras que otras apenas se están adaptando a estas dinámicas de desarrollo, y otras más desconocen completamente la lógica de la globalización.

El historiador Mauricio Archila en su libro Idas y venidas, vueltas y revueltas configura la protesta medioambiental desde la construcción de las identidades de los actores sociales, en las cuales existe una evolución en el contenido, los discursos y los avances. De lo que se consideraba una protesta de vecinos en contra de los malos olores de los mataderos, a la protesta de los ciudadanos por los proyectos de megaminería hay toda una maduración de las acciones colectivas en pro del ambiente. Existe una preocupación estatal por la preservación y la legislación del ambiente. La fundación del Instituto Nacional de los Recursos Naturales Renovables y del Ambiente —-Inderena-, en el año de 1968, le dio la importancia a la problemática ambiental en Colombia; sin embargo, 
las universidades son el principal espacio de discusión y defensa de la calidad ambiental y de la defensa ecológica, de hecho, de estas iniciativas universitarias aparece el Consejo Ecológico de la Región CentroOccidental -Cerco- (Archila, 2008, p.415).

La primera movilización ambientalista en Colombia se dio en el año 1979 cuando el proyecto modernizador de la Isla de Salamanca, en el departamento de Magdalena, produjo una serie de reacciones en rechazo a lo que significaban los daños ecológicos a la reserva natural. En la problemática ambiental es recurrente que afloren regionalismos; esto induce a pensar que las nociones de región y de medio ambiente son construcciones territoriales, y que las decisiones y posturas de las personas afectadas entran en conflicto con otros agentes. Para este caso en particular, consignas como Cachacos go home mostraron rechazo al proyecto que desde Bogotá planeaba cambiar la dinámica de la isla (Archila, 2008, p.414).

En la década de los ochenta la globalización de los ideales y las lógicas ambientales hace que distintas organizaciones no gubernamentales extranjeras se fijen en las dinámicas nacionales. Es tanto el interés por este tipo de problemas, que surge la idea de crear un Partido Verde, pero la violencia y la radicalización en el país hacen que tanto la presencia extranjera como la local posterguen esta idea. Solo hasta la Asamblea Nacional Constituyente de 1991 el Partido Verde apareció como una nueva opción política, sin embargo, no tuvo una acogida popular, pues solo obtuvo ocho mil votos en la consulta. Se podría considerar que en el siglo xx no existió un movimiento ambientalista propiamente dicho, en cambio, distintos partidos políticos anexaron en su agenda la problemática medioambiental. En concordancia con lo anterior, el ambientalista Gustavo Wilches definió la situación en Colombia de la siguiente manera: "Los movimientos sociales se están ambientalizando" al hablar del apoyo por parte de sectores políticos, estudiantiles y gremiales (Archila, 2008, p.415). 
En la década de 1990 los intereses de las empresas transnacionales impulsaron el desarrollo minero-energético en los países latinoamericanos, en parte, por las grandes rentabilidades y por las garantías que los gobiernos le dieron a la inversión extranjera, y por el endeudamiento producto de la deuda externa que tenían con organizaciones transnacionales como el Banco Mundial. La llegada de estas empresas al país modificó, notablemente, las relaciones sociales por cuenta del desarrollo económico local; los pobladores, que por siglos se dedicaron a la minería artesanal, se encuentran, en la actualidad, en una encrucijada por el impulso globalizatorio que menoscaba una minería a baja escala frente a una política extractivista a gran escala que no guarda ninguna relación con un patrimonio histórico y cultural. Esta problemática es calcada y reproducida en la mayoría de municipios de tradición minera de Colombia, un ejemplo claro de dicha coyuntura es la zona geográfica y natural mejor conocida como Santurbán.

La aparición de trasnacionales en zonas apartadas del país coincide con las nuevas luchas contra el neoliberalismo. Los actores sociales protagonistas de las movilizaciones se oponen a las relaciones sociales capitalistas basadas en la propiedad privada de los recursos y a la gestión burocrática de los bienes públicos (Laval y Dardot, 2015). De esta manera, las luchas ambientalistas por los bienes comunes muestran tensiones entre lo local y lo global. En la región, es decir en América Latina, existe una concepción negativa de la globalización, en parte, porque ha sido de las primeras regiones en sufrir los recortes estructurales propuestos por el Fondo Monetario Internacional y también por ser testigo de las concesiones que hacen los gobiernos de turno con grandes firmas extranjeras que explotan los recursos naturales.

El neoextractivismo de las empresas petroleras y mineras modela las sociabilidades de las regiones apartadas de los grandes centros urbanos, donde la presencia estatal y el desarrollo institucional son minúsculos. Esta relación de interés y codicia extralimitada es común en la historia nacional desde mucho tiempo atrás, en parte por la debilidad del mis- 
mo Estado, el cual termina sirviendo a intereses particulares. Quienes terminan sufriendo las consecuencias de esta relación de extracciónproducción, es decir, entre ganancia a toda costa vs. recursos naturales, son las personas de los sectores más olvidados de esta relación.

\section{La construcción social, política y cultural del páramo}

El páramo se puede pensar como la reunión de factores históricos, sociales, biológicos y geológicos que deben ser tenidos en cuenta en su interacción al momento de forjar una noción amplia del término. Constituyó una frontera natural y social que sirvió de refugio para los pueblos indígenas, colonos y campesinos (Buitrago, 2016). Por esta razón, funciona como un espacio de silencio, de lejanía, donde se mezclan la realidad y la ficción, la riqueza y la pobreza, el olvido institucional con el interés por parte de entidades privadas transnacionales. En otras palabras, es un sitio de encuentro y desencuentro donde el agua $\mathrm{y}$ el oro pueden coexistir, aunque en el constructo social los intereses económicos parezcan antagónicos.

Como es de esperarse, al ser un espacio natural y social rico en contradicciones, este ecosistema empieza a ser estudiado por geógrafos, biólogos, ingenieros ambientales y, en las últimas décadas, por profesionales de las ciencias humanas. Según Emerson Buitrago, los estudios sobre el páramo han sido direccionados desde una perspectiva positivista del realismo epistemológico ${ }^{2}$, en la que conocer y clasificar son los dos factores que conducen a otro que es definir, es decir, poner límites (Buitrago, 2016, p.140). La delimitación de un espacio tan característico de Colombia se convierte entonces en una de las principales tareas para su conocimiento. Según el Ministerio de Ambiente, el páramo abarca

2 Es la tesis que afirma que es posible conocer el mundo tal como es en sí mismo. Es decir, el conocimiento alcanza las cosas en sí, y las describe y explica en su propia naturaleza, tal como son. Según el realismo epistemológico, el conocimiento científico no depende de los sujetos, ni del consenso, ni de ningún factor social o psicológico (Cassini, 1992). 
aproximadamente el 2,6\% de la superficie del país y cerca del 9,4\% del departamento de Santander (Ministerio del Medio Ambiente, 2002), aunque se establece que esta cifra aumenta a un millón de hectáreas más con la delimitación llevada a cabo en el año 2013, que pasa de una escala de 1:100.000 a una nueva escala de 1:25.000. Lo anterior evidencia que Colombia cuenta con cerca de tres millones de hectáreas de ecosistema de páramo (Silva, 2013).

La perspectiva realista epistemológica configura la construcción del páramo y deja por fuera múltiples variables que no solo delimitan un espacio natural, sino que condenan a las personas que viven allí a adaptarse a condiciones y lineamientos globalizados que en su mayoría desconocen. Sin embargo, la evolución del paradigma hace que la delimitación del páramo tenga en cuenta iniciativas sociológicas, históricas y, sobre todo, humanistas. Esta alianza entre lo natural y lo social es posible por la ejecución de investigaciones ecologistas que cambian la configuración del páramo como una latitud y una altitud determinadas para ser concebido como "el espacio productor de agua en el país y una zona de gran importancia para la conservación” (Buitrago, 2016, p.142).

Este triunfo para la ecología produce una bifurcación. El paso de un ideal utópico de conservación y la construcción social del espacio geográfico de páramo deriva en tensiones por el oficio de la extracción aurífera y la preservación del agua. En otras palabras, la protección social del páramo como un componente para generar y preservar el agua potable, que nutre grandes centros urbanos, entra en confrontación con la actividad minera de la zona que por siglos ha sido explotada por sus pobladores, en una relación ancestral de mutualismo, donde el hecho de ir a la mina es un ritus, un tributo no solo a las capacidades físicas de quien extrae el mineral, sino a la experiencia necesaria para hacerlo y al acto de comunicación que va de generación en generación, mediante el cual se perfecciona un oficio artesanal. Pero esta técnica, que permite dar la subsistencia a los pobladores de tan agrestes ecosistemas, es equiparada con el extractivismo desmesurado y dañino de 
mineras transnacionales que no sienten la menor empatía por el paisaje y solo piensan en términos de extracción y capitalización.

Actualmente, el páramo se ha convertido en una bandera política para ganar votos o en una excusa violenta para la polarización del país. Si bien existen recelos y tensiones entre los habitantes de la provincia de Soto Norte con los del área metropolitana de Bucaramanga, es necesario trascender más allá del oro y del agua y concentrarse en la protección de la región como una interdependencia entre los factores bióticos y abióticos. Pensar el páramo es pensar a la región como una dinámica de coexistencia que inicia entre las nubes y las montañas y va hasta la ciudad.

\section{La conquista del páramo}

\section{Proyecto Angostura}

La globalización como proceso político, económico y dinamizador de nuevas cotidianidades ha transformado de manera radical el futuro y la percepción del porvenir de las realidades latinoamericanas de manera significativa desde la década de 1990. Por ejemplo, Greystar llegó en el año 1994 y se hizo a terrenos sobre la falda de la montaña en lo que se conoce como el municipio de California. Este proyecto conocido como “Angostura”, implicó la compra de cerca de treinta mil hectáreas y una inversión de más de cien millones de dólares en la región. El gasto sin precedentes de Greystar en una región institucionalmente olvidada se fundamentó en el estimado de extraer cerca de dieciséis toneladas de oro al año (Molano, 2010), lo que convirtió a la zona en uno de los grandes proyectos de minería aurífera del mundo.

La llegada de la transnacional minera coincidió con la expedición de la Ley 99 de 1993. Esta ley, mejor conocida como Ley General Ambiental de Colombia, creó el Sistema Nacional Ambiental — Sina- y sistematizó los esfuerzos ambientales que se estaban dando en distintos laboratorios y centros científicos del país, en especial en las universidades, 
en torno a una problemática de extractivismo a gran escala que amenazaba con cambiar considerablemente el paisaje colombiano. Con esta nueva tendencia de explotación minera, los páramos son las principales víctimas, por esta razón se definieron las áreas de páramos y subpáramos como objeto de protección especial. Para evitar el empoderamiento de grandes hectáreas de estas zonas a títulos mineros, la Ley 373 de 1997 decretó:

En la elaboración y presentación del programa se debe precisar que las zonas de páramo, bosques de niebla y áreas de influencia de nacimientos acuíferos y de estrellas fluviales, deberán ser adquiridos o protegidos con carácter prioritario por las autoridades ambientales, entidades territoriales y entidades administrativas de la jurisdicción correspondiente, las cuales realizarán los estudios necesarios para establecer su verdadera capacidad de oferta de bienes y servicios ambientales, para iniciar un proceso de recuperación, protección y conservación. (Congreso de Colombia, 1997, art. 16).

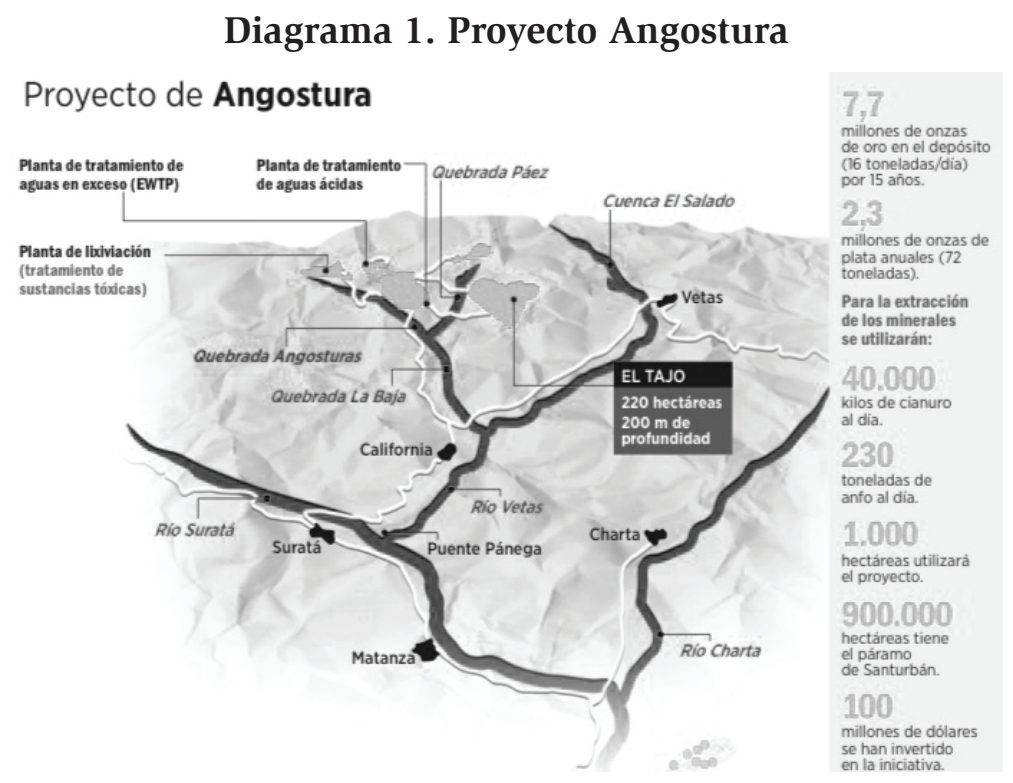

Fuente: Proyecto Angostura. El Espectador, 2010. 
La legislación ambiental no ha sido lo suficientemente fuerte para frenar la compra de títulos por parte de grandes mineras internacionales, las cuales han impulsado la construcción de carreteras, la profesionalización de algunos oficios y la seguridad social para quienes se dedican a estos trabajos, componentes que han mejorado la calidad de vida de los pobladores, y que anteriormente eran difíciles de encontrar en estas zonas apartadas del país, donde la imagen de la institucionalidad no llegaba. La presencia de las empresas mineras en la zona fomentó las extorsiones y secuestros por parte de las guerrillas que frecuentaban el sitio, lo cual hizo que el páramo dejara de ser un espacio mítico o una frontera olvidada, destinada para campesinos y actores sociales endógenos, y se convirtiera en una zona de conflicto, a tal magnitud, que fue necesario en 2002 crear los batallones de alta montaña como estrategia para controlar los corredores de narcotráfico y minería ilegal.

La expansión del "Proyecto Angostura" ha sido la piedra angular del desarrollo económico de los municipios de Vetas y California, poblaciones que, por tradición, han tenido como sustento la economía aurífera artesanal, la cual han dejado de lado para enlistarse como empleados en la multinacional. El "Proyecto Angostura” requiere de una licencia por parte del Ministerio de Ambiente que le permita explotar esta zona de manera libre hasta el año 2025. Pero los proyectos de Greystar van mucho más allá de la explotación a cielo abierto en la extracción aurífera:

la transformación del paisaje es radical. El proyecto abrirá un tajo de doscientos veinte hectáreas con una profundidad de doscientos metros en la parte más alta de la montaña. Para el tratamiento del mineral se harán otros dos espacios: uno de ciento diez hectáreas sobre la quebrada Angostura y otro de noventa hectáreas sobre la quebrada Páez. (Molano, 2010).

Cabe resaltar que ambas quebradas van a dar al río Suratá, el cual alimenta de agua potable al área metropolitana de Bucaramanga y a los poblados que se benefician en su recorrido. (Diagrama 1). 
La presentación del “Proyecto Angostura” causó escándalo e indignación en diversos sectores de la población, desde el espectro político, con grupos como el Polo Democrático Alternativo hasta el Partido Verde; hasta estudiantes y ciudadanos con sensibilidad ambiental. De inmediato, un organismo encargado del Comité por la Defensa del Páramo de Santurbán se pronunció al respecto:

El comité no está en contra de los proyectos mineros, está en contra de los proyectos que afectan la posibilidad presente y futura del agua para el área metropolitana y algunas poblaciones del departamento de Santander y Norte de Santander. Estamos planteando propuestas de desarrollo alternativo para la región. (Molano, 2010).

Con las comunidades divididas entre quienes apoyan el proyecto, porque garantiza un sustento y una oportunidad laboral, y quienes lo desaprueban, por el costo ambiental que esto significa para el futuro, empezó el debate legal y el enfrentamiento entre capitales políticos alrededor de estas lógicas y programas del Gobierno. Para el año 2010, el presidente Juan Manuel Santos Calderón habló de las “locomotoras del desarrollo”, una de ellas la del sector minero. El enunciado presidencial aparentemente daba vía libre a las extracciones, pero chocó con la sentencia de la Corte Constitucional sobre la Ley 1382 que prohibió cualquier tipo de minería en estos ecosistemas. A partir de este momento la Procuraduría General de la Nación, en cabeza de Alejandro Ordoñez Maldonado, inició un proceso de dilatación del permiso por parte del Ministerio de Ambiente y, posteriormente, el 21 de diciembre de 2010 aconsejó no otorgar la licencia minera al "Proyecto Angostura" por la ubicación en zona de páramo (Celedón, 2010). Sin embargo, con esto no terminó la disputa sobre el proyecto. Tanto Greystar como las fundaciones ambientalistas no han dado su brazo a torcer.

El 25 de enero de 2011 se realizó el Foro sobre el "Proyecto Angostura”. El evento organizado por la Fundación Participar reunió al Chief Executive Officer - CEO- de Greystar, Steve Kesler, representante de 
quienes estaban a favor del proyecto, y al exministro de Ambiente, Manuel Rodríguez, como representante de quienes estaban en contra, quien señala que el $54 \%$ del "Proyecto Angostura" se encuentra a más de tres mil cien metros de altura, es decir que es inviable, según la legislación. Por su parte, el CEO de Greystar aseguró:

Vamos a desarrollar programas para reincorporar todas las hectáreas impactadas por nuestras actividades en todos los ecosistemas en páramo y sub-páramo y bosque andino y no solamente la recuperación de este terreno, sino también vamos a desarrollar un programa de recuperación de seis hectáreas de páramo, sub-páramo y bosque andino por cada una impactada por nuestras actividades. (Celedón, 2010).

Lo que se consideraba un problema de índole regional, incluso rural, saltó a la esfera nacional, de manera imprevista, a través de los medios de comunicación nacionales, porque supuestamente existía tráfico de influencias con la expedición de las licencias de explotación minera. En entrevista a un medio nacional, el ministro de Minas, Carlos Rodado, aseguró que el proyecto podía realizarse, siempre y cuando se hicieran placas de lixiviación ${ }^{3}$; además, reprochó la actitud del Ministerio del Ambiente, por hablar de manera ambigua y no definir el futuro del proyecto.

Ante la dilatación del proceso en las cortes y la dilación de los ministros sobre la decisión final, por el peso político y económico que suscita dar la aprobación o negación del Proyecto Angostura, la población decidió ejercer presión. En Bucaramanga, desde tiempo atrás, existían colectivos ambientalistas y ecologistas preocupados en mayor medida por el impulso de una cultura verde, mediante la cual se promueva el desarrollo sostenible de la ciudad. Gracias a los medios de comunicación y a la importancia que estos dieron a la problemática, los colectivos ambien-

3 Proceso de extracción en el que se quitan residuos sólidos mediante un disolvente líquido; usado principalmente en la extracción minera como un proceso químico con ácido donde se usa la cianuración del oro. 
tales reforzaron su voz y ganaron protagonismo, hasta el punto que la misma Federación Nacional de Comerciantes - Fenalco - anunció para el 25 de febrero de 2011 una marcha en contra del "Proyecto Angostura" bajo el lema “¡Defendamos el agua, defendamos la vida!”

En los días previos a la gran marcha, la presión contra Greystar y el "Proyecto Angostura" aumentó considerablemente. La Corporación Autónoma Regional para la Defensa de la Meseta de Bucaramanga - $\mathrm{CDMB}$ - ratificó la sanción a la multinacional de sesenta salarios mínimos legales vigentes por múltiples motivos, entre los que se destacaban problemas con el tratamiento de aguas ácidas, estabilización de los taludes y desviación de la quebrada La Perezosa, sin pedir permiso (Celedón, 2010). El prontuario de Greystar por desacato a la legislación ambiental constituyó un antecedente de lo que le puede deparar el "Proyecto Angostura” al Páramo de Santurbán.

\section{Fotografía 1. Gran Marcha Defendamos el Agua de Bucaramanga}

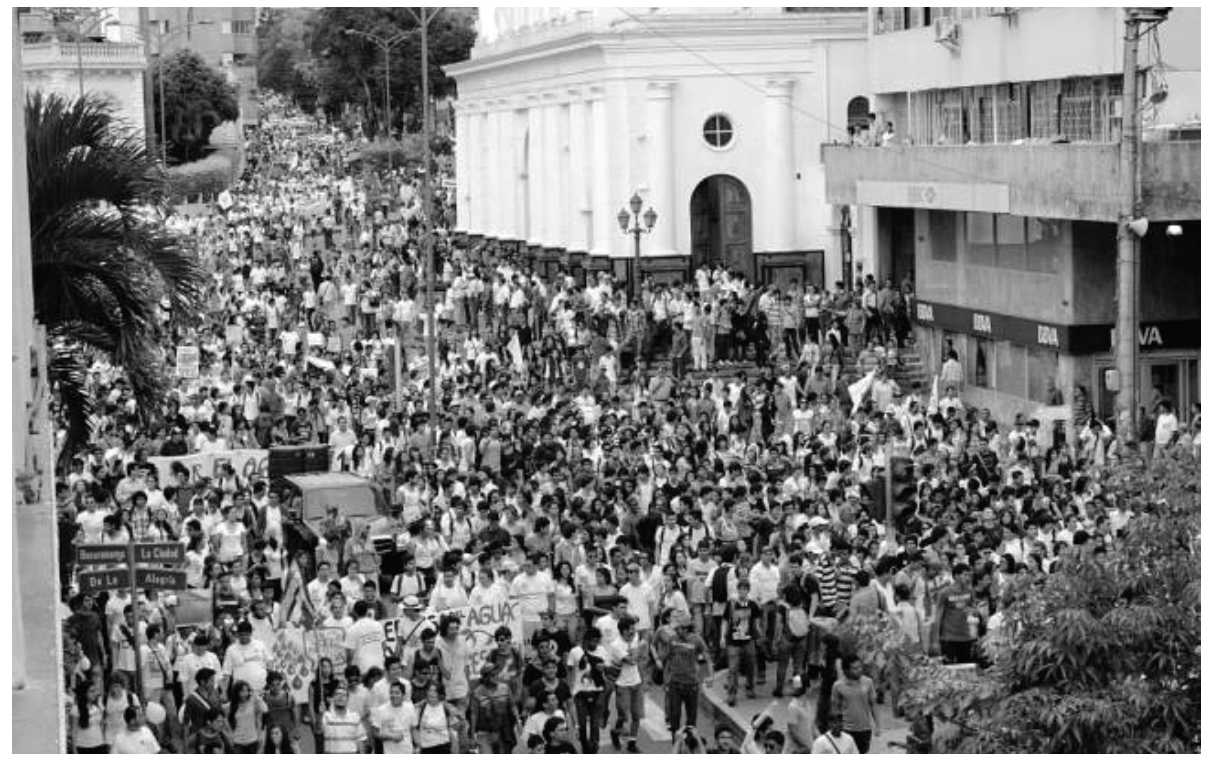

Fuente: Vanguardia Liberal. Masiva participación en marcha por el agua. Bucaramanga. 25 de febrero de 2011. 
El boom mediático en que se convirtió Santurbán no solo se elabora con tecnicismos, estudios especializados y querellas legislativas. Existe un redescubrimiento de Santurbán por parte de la comunidad, logrado a través del afianzamiento del cariño y el sentido de pertenencia de que es posible defender lo que antes había sido invisible. La riqueza del paisaje, la montaña que se adentra en el cielo y la tranquilidad que transmite un ambiente único y a la vez delicado capta la atención de cientos de personas que sienten la necesidad de retratar y compartir lo que puede desaparecer con la megaminería. Como estrategia para generar sensibilidad, la Universidad Industrial de Santander convocó a un concurso de fotografía denominado "Los páramos, un pasaporte al futuro". La apuesta de la universidad es acercar el páramo a la comunidad y hacer presencia en las regiones.

\section{El nodo: la movilización}

El 25 de febrero de 2011 entre 30000 y 40000 ciudadanos del área metropolitana de Bucaramanga se hicieron presentes en la movilización por la defensa del Páramo de Santurbán (fotografía 1). La marcha que reunió colectivos, ciudadanos interesados y gremios como Fenalco fue todo un éxito, tal y como lo señala el director ejecutivo de dicha entidad:

La Gran Marcha Defendamos el Agua de Bucaramanga fue una verdadera audiencia pública que logró reunir a padres y madres de familia; nietos y abuelos; empresarios y trabajadores; comunidades religiosas; estudiantes de colegios y universidades; transportadores; grupos cívicos, ambientalistas y de la tercera edad de Bucaramanga, Floridablanca, Girón y Piedecuesta. (Vanguardia Liberal, Masiva participación en marcha del agua, 2011).

Desde la teoría de los movimientos sociales, los nuevos movimientos, entre los cuales se destacan el estudiantil, el ambiental y el de género, son delimitados por la naturaleza homogénea de sus participantes; el movimiento estudiantil, por ejemplo, es apoyado por estudiantes; el de género por mujeres activistas Pero esto no pasa en las coyunturas regionales. El movimiento ambiental es capaz de recoger una multiplicidad 
importante de actores sociales, sin importar el rango de edad, su nivel de educación o el espectro político. El reconocimiento sobre la importancia del ambiente y la legitimidad de las peticiones hace que, incluso adversarios políticos, se unan en torno a un fin.

Se podría considerar que el agua, como recurso vital, es la única razón que recoge los lineamientos de un nuevo movimiento social de manera local: la preocupación por un futuro en el cual su acceso está en riesgo atormenta a la población y la mueve a salir y a participar. En otras palabras, se trata de una realidad modulada por una lógica de bienestar doméstico y básico, en la que el agua es una necesidad primaria. En las dinámicas de la movilización no hay una conciencia sobre la posibilidad de que también se pueda crear un movimiento antiglobalización frente a la presencia de una minera transnacional o la destrucción del paisaje, que debe ser protegido por tener flora y fauna única en el planeta. Es la amenaza sobre el recurso vital lo que dinamiza la movilización.

El éxito rotundo de la marcha y la presión que ejercieron las redes sociales hizo que otros organismos transnacionales se pronunciaran al respecto, como es el caso del Parlamento Andino que en la sesión realizada entre el 23 y el 25 de febrero de 2011 le comunicó a Greystar:

Desistan del propósito de realizar el Proyecto Angostura de explotación minera en el Páramo de Santurbán, Santander, dado que se pone en riesgo la vida de seres humanos de un país de la Región Andina, signatario de instrumentos internacionales de Derechos Humanos, Acuerdos y Protocolos Ambientales. (Celedón, Greystar, desistan del Proyecto Angostura: Parlamento Andino, 2011).

Por su parte, la multinacional le respondió con un contra-comunicado:

Greystar garantiza a los habitantes de la provincia de Soto Norte, Bucaramanga, y en general a los santandereanos, que el proyecto no afectará ni la calidad ni la cantidad del agua que se consume en la región y en la capi- 
tal del departamento. (Celedón, Greystar, desistan del Proyecto Angostura: Parlamento Andino, 2011).

El 4 de marzo se realizó una audiencia pública en la cual distintas personas expusieron las perspectivas que creían fundamentales en la resolución del "Proyecto Angostura”. Entre las intervenciones se destacó la del entonces gobernador Horacio Serpa:

El Gobierno de Santander considera que el Proyecto Angostura de la firma Greystar genera alto riesgo para la salud, la vida y el ambiente sano de los habitantes de California, Vetas, Suratá y toda el área metropolitana de Bucaramanga, por lo tanto, la Gobernación de Santander solicita al Ministerio de Medio Ambiente negar la licencia ambiental para la empresa.

Por su parte, el alcalde de California Medardo García pide que se conceda el permiso para el Proyecto Angostura y critica la posición de los ambientalistas que solo se acordaron de proteger el agua y el medio ambiente en estos instantes, cuando el Páramo de Santurbán siempre ha existido. (Peñaloza, 2011).

Esta es la dinámica que ha caracterizado la problemática en torno a Santurbán. Por un lado se encuentran los ambientalistas, personas que viven en el área metropolitana de Bucaramanga; por el otro, los residentes de la región de Santurbán, de los cuales un sector importante ve en el proyecto de megaminería una oportunidad para reactivar la economía. La tensión entre estos dos polos —el urbano y el rural- ha comenzado a ser cada vez más divergente. Entre tanto, la transnacional, por órdenes recibidas desde Canadá, presionó la firma del permiso. No solo hay una tensión en esta coyuntura glocal, un impacto local como este repercute de manera directa en las dinámicas económicas internacionales. Tan solo el día de la audiencia pública, las acciones de Greystar retrocedieron un $14 \%$ en la Bolsa de Toronto. La razón es la mala prensa que se le está haciendo a la empresa en la comunidad internacional y las pérdidas por la pausa en la ejecución del Proyecto Angostura. 
La audiencia pública registró cerca de cuatrocientas setenta ponencias, pero solo alcanzaron a pasar treinta. Los ánimos exaltados no propiciaron un diálogo constructivo entre las partes. Las protestas de los habitantes de Bucaramanga, como dar la espalda mientras el alcalde de California argumentaba las ventajas del proyecto para la región, y la arremetida del éste contra los ambientalistas por considerar que protestaban por moda, exaltaron aún más los ánimos. De igual manera, los habitantes de la provincia de Soto hablaron en contra del senador Jorge Enrique Robledo, a quien llamaron "politiquero y oportunista". Las agresiones dejaron de ser verbales cuando algunos asistentes tildaron de "comprado e ignorante" al concejal Víctor Arias, quien molesto bajó de la tarima a agredir a quienes le gritaban, hasta que intervino la policía (Celedón, Por trifulca terminó la audiencia de Angostura con solo 30 ponencias, 2011). Los representantes del Ministerio de Ambiente y de la Procuraduría establecieron quince días para decidir el futuro del proyecto.

Mientras la tensión aumentaba en Santurbán y los políticos de la región están divididos entre quienes van en contra y quienes apoyan la realización del “Proyecto Angostura”, el ministro de Minas se reunió con los participantes en la tercera jornada de Feria Minera Prospectors \& Developers Association of Canada en Toronto. Allí, el ministro expresó que el Gobierno estaba evaluando la disminución de impuestos a empresas mineras:

todo esto tuvo algún impacto sobre las compañías mineras y lo que el Gobierno está analizando ahora es cómo disminuye o reduce la tasa de impuesto a la renta corporativa, de tal manera que esto no solamente compensaría, sino que dejaría a las empresas en una mejor circunstancia cuando se comparen los dos efectos. (EFE, 2011).

Los directivos de la firma Greystar criticaron que Colombia cambiara las reglas de juego en las licencias ambientales, pero el ministro fue 
enfático en responder que el problema no era de la legislación, sino de la calidad de los estudios presentados por la minera (EFE, 2011).

El 18 de marzo de 2011, en una declaración, el ministro de Minas y Energía anunció que, por decisión unilateral, Greystar decidió retirar la solicitud de licencia técnica, es decir, la solicitud de aprobación del programa de trabajos y obras que se hizo por parte de Ingeominas, y también retiró la solicitud de licencia ambiental para el proyecto de explotación de oro en la zona de Santurbán en el departamento de Santander. La noticia fue recibida con alegría por parte de los colectivos que se movilizaron:

Es una primera batalla ganada que favorece finalmente no sólo nuestra agua, sino también el derecho de las futuras generaciones a gozar de un ambiente sano", afirma Orlando Beltrán, vocero del Comité Prodefensa del Páramo de Santurbán. (Celedón; Minminas, 2011).

La noticia fue considerada como una victoria en el área metropolitana de Bucaramanga, aunque no fue igual en las zonas de California y Vetas. Un amplio sector de la población tuvo un sentimiento de molestia al enterarse de que Greystar desistió del proyecto. Tal fue su disgusto que una asonada de cerca de treinta personas atacó con palos y piedras a reporteros que cubrían el desarrollo de la noticia. Según la periodista, la gente manifiesta que parte de la culpa de que el proyecto se retire es por la presencia de los medios de comunicación y la orientación que le han dado a la noticia (Vanguardia Liberal, Equipo periodístico del Noticiero CM\& fue agredido en California, Santander, 2011). Fueron necesarios cerca de catorce policías para socorrer al equipo periodístico. Pero los sentimientos encontrados no duraron demasiado. En un comunicado del 19 de marzo firmado por el CEO de Greystar, se anunció el retiro de la propuesta de extracción a cielo abierto, pero se abrieron las posibilidades de minería subterránea.

Durante los siguientes años, la dinámica de Santurbán con el "Proyecto Angostura” cambió de manera sustancial. En primer lugar, Greystar 
dejó de existir y cambió su razón social a Eco Oro. Esta iniciativa fue la primera de una escalada por reactivar los proyectos mineros desde la reunión de la junta directiva del 19 de agosto de 2011 (Colprensa, 2011). Todas las funciones tanto de ingeniería como económicas se centraron en la nueva empresa, el cambio se sintió no solo en la reactivación de labores en Vetas y California, con la extracción subterránea, sino en la Bolsa de Toronto.

Tal es el éxito de las nuevas extracciones que las estadísticas de Eco Oro para la próxima década llegan a 4332 millones de dólares por cada setenta y seis toneladas de oro (Celedón, 2013). Pero los planes de Eco Oro fallaron, pues en 2014 el Ministerio de Ambiente junto al Ministerio de Minas se comprometió a revelar la nueva delimitación de las zonas de páramo; con esta iniciativa legal, las proyecciones de Eco Oro quedaron en simples predicciones. El 19 de diciembre de 2014 se anunció que 98.954 hectáreas serían protegidas frente a cualquier forma de extracción minera y que se incentivarían las actividades agrícolas con una inversión de quince mil millones de pesos (Revista Semana, 2014).

El drama de los municipios que bordean el Páramo de Santurbán va más allá de la puja entre ambientalistas y mineros. El olvido institucional y los planes de ordenamiento territorial inacabados condenan a la zona a ser un pueblo fantasma; decenas de edificaciones sin terminar, que fueron previstas para los mineros, que nunca llegaron, son pruebas de los proyectos de reactivación económica que jamás se cumplieron.

Pero la problemática no es blanca y negra, el claroscuro de lo social trastoca realidades como la de los mineros artesanales. Según el representante de los pequeños mineros de California, Leonidas Arias:

Nosotros hemos sido los que hemos cuidado el páramo y el agua por muchísimos años. Yo quiero que vean lo que es el Páramo de Santurbán. Porque en el país se tiene la idea de que está acabado y de que lo hemos dañado. ¡No señores! Nosotros somos mineros desde hace muchas gene- 
raciones y queremos seguir siendo mineros. Queremos que sepan que lo vamos a ser de una manera responsable. (Revista Semana, 2014).

Las tensiones generadas por la problemática de Santurbán se mantienen hasta hoy. El proceso de defensa del medio ambiente, pero también la necesidad de un desarrollo económico sostenible son dos ideas que invitan al debate y a la construcción de una propuesta económica, política y social que sea consecuente con las necesidades de las poblaciones de la zona del Páramo de Santurbán y las poblaciones aledañas, que consideran al páramo como una joya hidrográfica de flora y fauna importante no solo para la región, sino para el mundo.

\section{Conclusiones}

La problemática de Santurbán mejor conocida como el "Proyecto Angostura” tiene la misma naturaleza de las problemáticas contemporáneas: la emergencia en la viralidad y en la inmediatez de la denuncia que amenaza con destruir un entorno natural; sin embargo, ignora toda una tensión histórica que viene desde la década de 1990, cuando se invitaron diferentes transnacionales mineras a que invirtieran en el país como alternativa para la recuperación de la golpeada economía nacional.

Este primer antecedente es muy importante para comprender que la aparición en el año 2011 del "Proyecto Angostura" no es un proyecto del presidente de turno, sino que es uno de los tantos fenómenos de la política gubernamental que dirige el horizonte nacional desde las últimas tres décadas. Lo que se pretende hacer en Santurbán no es descabellado, es, más bien, el efecto de una política ya acordada y aceptada. Lo verdaderamente novedoso para el año 2011 fue la movilización ciudadana, pues mostró que era posible ejercer oposición frente a negocios que han sido acordados entre grandes inversionistas extranjeros y el Gobierno nacional. 
Con la tensión social emergieron los pro-mineros y los pro-ambientalistas. En medio de esta polarización se vislumbran las señales que han marcado la configuración social de los pueblos tales como el olvido institucional, el arribismo, el cortoplacismo para desarrollar e implementar planes de ordenamiento territorial y la laxitud burocrática entre ministerios, contralorías y procuradurías al momento de definir y dar una respuesta frente a la presión de gruesos capitales extranjeros.

La movilización en contra del extractivismo une en la realidad urbana, pero divide la ruralidad por el desencanto y la molestia causados por la pobreza y por la falta de oportunidades. Las respuestas frente a estas situaciones son las vías de hecho, la intolerancia y la agresión al otro, se podría afirmar, entonces, que el país no ha cambiado mucho desde la segunda mitad del siglo xx, aún se mantienen vivas las pulsiones con las cuales la violencia ha sido la forma idónea de mostrar el desacuerdo y de ejercer presión que no es ignorada por el Estado.

El principal problema no es la extracción de oro; de hecho, esta actividad se ha constituido en una forma de vida, de estar en comunidad y se ha convertido en el patrimonio de municipios como Vetas y California. Tampoco lo es la preocupación ecológica en las ciudades ante problemáticas mal informadas, que son moldeadas solo por lo que los medios de comunicación quieren presentar, mientras que estos tienen la necesidad de vender y generar controversia. El verdadero problema es la falta de normatividad, pues esta ausencia obliga a competir al pequeño minero artesanal con la megaminería neoextractivista. El resultado es una lucha desigual, en la cual la megaminería puede hacer en quince años de extracción lo que el pequeño minero no hace en cuatrocientos: extraer todo el oro a la par que destruye el páramo, vende espejismos de progreso y globalización. 


\section{Referencias}

Archila, Mauricio (2008). Idas y venidas, vueltas y revueltas. Bogotá: Cinep e Icanh.

Berardi, Franco (2007). La generación post-alfa. Buenos Aires: Tinta Limón.

Buitrago, Emerson (2016). Limitaciones y delimitaciones de los páramos en una Colombia posacuerdo. En G. D. Ambiente, Extractivismo y posconflicto en Colombia: retos para la paz territorial. Bogotá: Universidad Nacional de Colombia.

Carson, Rachel (2005). Primavera silenciosa. Madrid: Crítica.

Cassini, Alejandro (1992). Realismo epistemológico, referencia y verosimilitud. Revista Hispanoamericana de Filosofía, 24, 3-33.

Castro-Gómez, Santiago (2015). Revoluciones sin sujeto: Slavoj Zizek y la critica del historicismo posmoderno. Bogotá: Akal.

Celedón, Nohora (8 de enero de 2010). Procuraduría pide declarar inexequible reforma al código minero. Vanguardia Liberal.

Celedón, Nohora (2 de marzo de 2011). Greystar, desistan del proyecto Angostura: Parlamento Andino. Vanguardia Liberal.

Celedón, Nohora (5 de marzo de 2011). Por trifulca terminó la audiencia de Angostura con solo 30 ponencias. Vanguardia Liberal.

Celedón, Nohora (18 de marzo de 2011). Greystar desiste del proyecto Angostura: Minminas. Vanguardia Liberal.

Celedón, Nohora (20 de febrero de 2013). 2.7 millones de onzas de oro podría extraer Eco Oro por vía subterránea. Vanguardia Liberal.

Colprensa (18 de agosto de 2011). Greystar cambió de nombre a Eco Oro Minerals Corp. Vanguardia Liberal.

Congreso de Colombia (11 de junio de 1997). Ley 373 de 1997. Por la cual se establece el programa para el uso eficiente y ahorro del agua. Bogotá: Presidencia de la República. 
EFE (8 de marzo de 2011). Colombia considera rebajar impuestos a empresas mineras. El Espectador.

EFE (8 de marzo de 2011). Gobierno considera rebajar impuestos a mineras mientras critican trabas a la Greystar. Vanguardia Liberal.

Han, Byung-Chul (2013). El enjambre. Madrid: Herder.

Laval, Christian y Dardot, Pierre (2015). Común: ensayo sobre la revolución del siglo XXI. Barcelona: Gedisa.

Melucci, Alberto (2010). Acción colectiva, vida cotidiana y democracia. México: El Colegio de México.

Ministerio del Medio Ambiente (2002). Programa para el manejo sostenible y restauración de ecosistemas de la alta montaña colombiana. Bogotá: Minambiente.

Molano, Alfredo (22 de diciembre de 2010). La fiebre del oro en Santurbán. El Espectador.

Peñaloza, Mario (4 de marzo de 2011). Gobernador de Santander pide negar permiso a Greystar. Vanguardia Liberal.

Revista Semana (19 de diciembre de 2014). Delimitan 98.954 hectáreas del Páramo de Santurbán. Semana.

Silva, Javier (12 de octubre de 2013). Páramos suman un millón de hectáreas más de las que se creía. El Tiempo.

Vanguardia Liberal (25 de febrero de 2011). Masiva participación en marcha del agua. Vanguardia Liberal.

Vanguardia Liberal (18 de marzo de 2011). Equipo periodistico del Noticiero CM\& fue agredido en California, Santander. Vanguardia Liberal. 